and the prioritisation of calls according to the urgency of patient need is introduced, the opportunity exists to improve care across the spectrum of 999 callers. At the most urgent end, appropriately skilled and staffed ambulances can be dispatched without delay. At the less urgent end, there is the opportunity to explore other, possibly more appropriate responses than the current obligatory "lights and sirens" paramedic vehicle. The question of appropriateness of use recedes as not only difficult to measure but also of little relevance. The question becomes: "how can ambulance services best plan the cost effective provision of prehospital care so that varied healthcare needs expressed by the general public through 999 calls receive an appropriate response?" This requires ambulance services to understand their workload and factors which affect all types of demand, not in terms of appropriateness or otherwise, but in terms of patient type and condition, and social as well as clinical need.

1 Department of Health. Statistical bulletin 1997/12. London: DoH Statistical Service, June 1997.

2 Williams BT, Dixon RA, Nicholl JP. Provision of first contact care out of hours in four urban areas in England. BMJ 1985;291:1689-92.

3 Dale J, Green J, Reid F, et al. Primary care in the accident and emergency department: I. Prospective identification of patients. BMJ 1995;311:423-6.

4 Green J, Dale J. Primary care in accident and emergency and general practice: a comparison. Soc Sci Med 1992;35: 987-95.

5 Davis T. Accident department or general practice? BMJ $1986 ; 292: 241-3$.
6 Lowy A, Kohler B, Nicholl JP. Attendance at accident and emergency departments: unnecessary or inappropriate? J Public Health Med 1994;16:134-40.

7 Gill JM, Riley AW. Nonurgent use of hospital emergency departments: urgency from the patient's perspective. J Fam Pract 1996;42:491-6.

8 Young GP, Wagner MB, Kellermann AL, et al. Ambulatory visits to hospital emergency departments: patterns and reasons for use. JAMA 1996;276:460-5.

9 Billittier IV AJ, Moscati R, Janicke D, et al. A multisite survey of factors contributing to medically unnecessary ambulance transports. Acad Emerg Med 1996;3:1046-52.

10 McLeay GF, Hamilton D, Bowie P. Emergency ambulance service: an accident and emergency audit. Medical Audit News 1995;5:137-8.

11 Brown E, Sindelar J. The emergent problem of ambulance misuse. Ann Emerg Med 1993;22:646-50.

12 Pennycook AG, Makower RM, Morrison WG. Use of the emergency ambulance service to an inner city $A \& E$ department-a comparison of GP and 999 calls. J R Soc Med 1991;84:726-7.

13 Gardner GJ. The use and abuse of the emergency ambulance service: some of the factors affecting the decision whether to call an emergency ambulance. Archives of Emergency Medicine 1990;7:81-9.

14 Kongelf E, Lereim I, Hald K. Requests for ambulances for patients with acute diseases and injuries. Are ambulance services abused? Tidsskr Nor Laegeforen 1989;109:334751 .

15 O'Leary, Bury G, McCabe M, et al. Ambulance user analysis in an accident and emergency department. Ir Med J 1987;80:422-3.

16 Rademaker AW, Powell DG, Read JH. Inappropriate use and unmet need in paramedic and non-paramedic ambulance systems. Ann Emerg Med 1987;16:553-6.

17 Morris DL, Cross AB. Is the emergency ambulance service abused? BMJ 1980;281:121-3.

18 Gibson G. Measures of emergency ambulance effectiveness: unmet need and inappropriate use. Journal of the American College of Emergency Physicians 1977;6:38992.

19 Schumann LJ, Wolfe H, Sepulveda J. Estimating demand for emergency transportation. Med Care 1977;15:738-49.

20 NHS Executive. Developing emergency services in the community: the final report. London: NHS Executive, 1997:6.

\title{
Review of a general practice attachment for accident and emergency training
}

\author{
M A Howell, S P Cembrowicz, K Jones
}

Accident and

Emergency Medicine, Bristol Royal

Infirmary

M A Howell

Montpelier Health

Centre, Bristol

$S$ P Cembrowicz

Accident and

Emergency Medicine,

Frenchay Hospital,

Bristol

K Jones

Correspondence to: Mr M A Howell, Accident and Emergency Departmen Queen Alexandra Hospital Cosham, Portsmouth, Hants PO6 3LY.

\begin{abstract}
General practice secondments are being increasingly undertaken by specialist registrars in accident and emergency (A\&E) medicine. This paper describes how two A\&E trainees arranged general practice secondments and the experiences gained. There follows a discussion of the benefits to the general practice and trainees involved, together with a contemporary consideration of the interaction between general practice and $A \& E$ services in the UK. $(f$ Accid Emerg Med 1998;15:215-218)
\end{abstract}

Keywords: general practice attachment; training

To date, training in general practice or family medicine is not a formal requirement for accident and emergency (A\&E) or emergency medicine training in the UK, North America, or Australasia. However, in view of the considerable areas of overlap between $A \& E$ medicine and general practice, an increasing number of trainees in $\mathrm{A} \& \mathrm{E}$ medicine are arranging general practice attachments. We are the first to describe the sort of programme which can be arranged to match the needs of a busy general practice and an experienced $A \& E$ doctor. Each A\&E trainee spent a month with the practice; KJ in 1995 and $\mathrm{MAH}$ in 1997.

The general practitioner involved (SPC) had not previously encountered practices which had organised such attachments. General practice training practices use a variety of well established teaching and assessment tools for their registrars; SPC turned to some of these in order to plan the attachments.

\section{Aims of attachment}

Each party began by writing down their own aims for the attachment.

\section{Aims of attachment (SPC)}

- To demonstrate the life of a busy inner city practice (some of whose patients are frequent $\mathrm{A} \& \mathrm{E}$ attenders) and how the primary health care team works. In particular to show the $A \& E$ trainees aspects of patients' lives invisible to an $A \& E$ department (for example, medicine of families). 
- To respond to "learner centred" curriculum needs, for example specific topics.

- To extract knowledge/skills/attitudes from $\mathrm{MAH}$ and $\mathrm{KJ}$-for example lunch time talks, cardiopulmonary resuscitation training.

- To explain why some patients become "inappropriate attenders".

- To explore various methods of assessment-for example video/multiple choice questions/log book.

- To teach trainees how to become "streetwise".

- To make the attachment enjoyable as well as instructive.

\section{Aims of attachment (KJ, MAH)}

Knowledge - what is available in the community: general practitioners, health visitors, district nurses, social workers, community psychiatric nurses, etc.

Clinical teaching-for example ear, nose, and throat, dermatology, psychiatry, obstetrics and gynaecology.

Problems faced-health education, compliance, particular patient groups (for example homeless, drug addicts), social problems, poverty, alcoholism, repeated attenders.

Primary care-how a health centre is run, referral methods available, other services available, how fundholding works.

\section{Educational methods used in general practice}

Vocational training has been obligatory for general practitioners for some years. General practice training practices are approved by peer audit against national standards and are subject to regular reinspection. The general practice "curriculum" is very broad, and increasing emphasis is placed on assessments of various-kinds during the general practice registrar year to enable the trainer to certify that the trainee is competent to practise.

Multiple choice questions and modified essay questions detailing an unfolding clinical scenario are often used informally as well as being part of the Membership of the Royal College of General Practitioners (MRCGP) examination. However, most assessment during the year is relatively subjective, much depending on the one-to-one relationship between the trainer and registrar, for which protected time is set aside weekly. Summative assessment has recently been introduced for general practice training, whereby trainees pass (or fail) their training by means of a variety of formal assessments (including a two hour video of consultations).

Assessing knowledge, skills, and attitudes in a field as wide as general practice is a considerable challenge and various guides have been designed to help. One of these, the Bristol University Curriculum Guide for General Practice Trainees, ${ }^{1}$ is a broad framework of several hundred topics likely to be encountered in general practice, covering five areas: (1) health and disease; (2) human development; (3) human behaviour; (4) medicine and society; and (5) the practice. This is based on a syllabus designed by a Royal College of General Practi- tioners (RCGP) working party. ${ }^{2}$ Trainees are asked to score their knowledge of each topic from zero (no working knowledge) to three (able to teach the subject). Not surprisingly, the responses of the $A \& E$ trainees identified some areas for attention, comprising a few topics in area 1 , some in areas 2 and 3 , and most in areas 4 and 5.

We also used the RCGP general practice rating scales ${ }^{3}$ for a further self assessment of general practice related skills. This is a series of 25 headings, covering history taking, physical examination (general and specific skills), hypothesis formation and testing, aspects of management, use of records, emergency care, professionalism, and personal development.

Armed with the results of these self assessments, we planned our own syllabus to focus on during the attachments. We felt that this would help define areas to concentrate on in a "learner centred" approach, as A\&E trainees have a healthy variety of different experience. "Protected time" was essential; neither trainee had formal $A \& E$ commitments during their time with the practice, and SPC arranged interruption-free time together-not always easy in a busy practice.

The general practitioner and the practice SPC had worked as a clinical assistant in A\&E since 1975 . The practice area is adjacent to Bristol Royal Infirmary in the centre of Bristol. Many of the practice's patients present in crisis at the hospital A\&E department and SPC found that he knew almost half the department's regular attenders.

Montpelier Health Centre serves the needs of the population of the Montpelier and St Pauls areas of Bristol. It is currently (1997) being rebuilt and the practice is temporarily accommodated in Portakabins. The practice consists of six full time partners, one assistant, and one and a half general practice registrars (trainees), along with 30 other employed staff. There are 11500 patients on the practice's list, 800 of whom are homeless - many are registered as living on various park benches. A total of 270 patients are known substance abusers and 306 are known to be alcohol dependent.

The practice is one of significant cultural mix with many patients of immigrant origin including large numbers of Afro-Caribbeans, Asians, Vietnamese, and Somalis. There are also significant Hungarian, Polish, and Sicilian minorities. The social spectrum of patients ranges from professors (several) to tramps (many). Tuberculosis, tropical diseases, childhood malnutrition, and violent death are all occasionally encountered.

The practice is a fourth wave fundholding practice, with a fundholding budget of $£ 2.1$ million. This fund covers staff salaries, drugs, outpatient referrals, and planned surgery. It does not pay for emergency work, that is $\mathrm{A} \& \mathrm{E}$ attendances and emergency hospital admissions and treatment. 
Table 1 Type of problem seen by the two trainees (\%)

\begin{tabular}{lcc}
\hline & $M A H$ & $K \mathcal{F}$ \\
\hline Medicine & 29 & 38 \\
Obstetrics/gynaecology & 17 & 17 \\
Psychiatry & 14 & 7 \\
Orthopaedics and trauma & 13 & 10 \\
Ear, nose, and throat & 13 & - \\
Surgical & 5 & 5 \\
Paediatrics & 3 & 14 \\
Eye & 3 & - \\
Social/other & 3 & 9
\end{tabular}

Note: SPC uses "tripartite" diagnoses, physical/psychological/ social, and therefore could not classify the patients he sees in the same way.

\section{Integrating the $A \& E$ trainee into the practice}

General practitioners are self employed and do not receive a salary. Their income depends on correctly claiming various fees and allowances, meeting targets, and delivering items of service. Time had to be spent initially in learning how health promotion, new patient registration, screening, and claims are dealt with. All these are now income critical, and an untrained newcomer could cause unwelcome disruption to practice management and income. Therefore, careful initial orientation was vital. Learning computer skills was the first task as the practice now works "paperless".

Each A\&E trainee began with joint surgeries (that is trainee and SPC) twice daily with patients at 10 minute intervals. The trainee also accompanied SPC on daytime visits (average two each morning), later doing visits alone. By the end of the first week, MAH and KJ were competent with the computer system and were seeing 10 patients per surgery, initially at 15 , then 10 minute intervals. Over $20 \%$ of patients seen present as "emergencies", and an "open surgery" exists each weekday and Saturday morning for such cases. Each trainee kept a daily log book; table 1 shows the patient profile over the month.

\section{Tutorials}

We had tutorials three times weekly, each lasting approximately an hour, covering topics chosen from our initial assessment. In addition there was opportunistic informal teaching as topics arose. Formal tutorials included:

- The Leeuwenhorst definition ${ }^{4}$ of the primary care doctor

- Roles of the general practitioner

- Working on the street-how to stay alive and safe. Particularly relevant for the practice area, in the inner city

- General practitioner's terms and conditions of service (historical and contemporary)

- Fees and allowances

- General practice records (computer and manual)

- Health needs of different ethnic groups

- The physical, psychological, and social triad

- Inner city health care

- Fundholding-pros and cons

Time with the primary health care team Time was also spent with the treatment room nurses, a social worker, a district nurse, a health visitor, and with other team members. Visits were made to another health centre in the city, to several local hostels for the homeless, to a mother and baby hostel, and to the headquarters of the deputising service. As a result of this last visit, the practice and $M A H$ have offered training to staff at the deputising service in resuscitation; this being thought useful now that many sick patients arrive there out of hours and unannounced.

\section{Out of hours work}

Experience of out of hours work was an important part of our curriculum; examining patients at home is a very different matter from hospital experience. Working alone at night on today's city streets is not to be taken lightly, ${ }^{56}$ and the practice does not put general practice registrars on call overnight until they are well orientated and "streetwise". This usually takes several weeks. As a compromise, each A\&E trainee covered several days on call until $7 \mathrm{pm}$, with back-up from a nominated partner at home. Much of the out of hours work in the practice area involves acute psychiatry and MAH was involved in four assessments for admission under the 1983 Mental Health Act during a single weekend day on call. A way of acquiring more experience of out of hours work during a brief attachment would be to accompany a deputising service doctor for one or more (usually 20 visits during a five hour shift), and we plan to arrange such an attachment in the future.

\section{Costs and benefits to the practice}

Benefits for the practice included 180 extra appointments per A\&E trainee month-saving the practice a number of locum sessionsparticularly welcome at a busy time of the year. The A\&E registrars also provided a number of instant trauma/surgical/orthopaedic opinions, as well as a training session for staff and partners in the new Resuscitation Council guidelines for cardiopulmonary resuscitation.

SPC found the training commitment stimulating but time consuming. General practice training practices are paid a training grant of $£ 5140$ per annum for the work involved in training. If $A \& E$ attachments are to be established on a large scale, an agreed training fee could be considered to ensure that protected time can be set aside, for example by employing extra locum cover. However, the whole issue of charges for training attachments is a broad one and the authors are not sure that such funding could be made available.

\section{Discussion}

A formal evaluation of such a brief attachment is difficult. All parties not only enjoyed the attachments but also felt that they had gained from each others' knowledge and experience, as well as having achieved most of the identified mutual aims.

Our main difficulty was in achieving exposure to a reasonable volume of out of hours work, mainly because of lack of time and the question of safety. Out of hours home visits in an unfamiliar inner city area, with patients she did not know, were particularly difficult for $\mathrm{KJ}$. They were certainly an educational experience, 
but the relatively short time available for initiation into this work was not sufficient to prepare her fully. The A\&E environment can be a threatening one, but in a different way to that posed by being alone outside hospital.

None of us initially knew quite what to expect from this attachment, nor how best to focus the general practice month to contribute to A\&E training. Our "learner centred" approach seemed to help us identify a syllabus based upon recognised needs and interests; each $A \& E$ trainee felt that their own needs were fulfilled. We thought that the use of video techniques would be of value, bearing in mind their large role in general practice training.

Our month was fairly intense; the attachment could have been longer. However, there are many other core curricular needs to be met during the five years of higher specialist training in $A \& E$ medicine.

Since our first attachment in 1995, new funds- $£ 45$ million per year-have been negotiated to change the way that general practice out of hours work is carried out, by developing improvements in the service for the sake of doctors and patients alike. The Department of Health has avoided opening the Pandora's box of pricing general practice out of hours work separately, which would imply enabling a separate service to arise. General practitioners retain 24 hour responsibility for their patients' care. They must therefore deal with all out of hours calls themselves, or arrange for this to be done on their behalf.

General practices are increasingly using their share of new development money to form cooperatives, start primary care centres, or pay commercial deputising services to cover their out of hours responsibilities. Other general practice developments which could have some bearing on $A \& E$ departments include setting up pilot " 888 " hotline phone services, which contract to provide skilled phone advice on a broad range of urgent situations, and creating special arrangements for seeing violent patients in secure surroundings.

A\&E departments are funded differently to, and are distinct from, general practice services; there is no question of the two services somehow becoming "merged". Rather than a threat, these energetic new developments may be seen as an opportunity for fruitful cooperation between $A \& E$ departments and general practices.

\section{Conclusion}

Objective assessment of any secondment is difficult, but we hope that this account of our attempts to apply established general practice training techniques to an $\mathrm{A} \& \mathrm{E}$ secondment is of interest. The authors would strongly recommend a four week full time secondment to a training general practice for all specialist registrars in A\&E medicine. All parties benefited from the attachments and the experiences were enjoyable as well as, at times, challenging.

1 Bristol University. Curriculum guide for general practice trainees. Bristol: Bristol University, 1989.

2 Royal College of General Practitioners. The future GP learning and teaching. London: Royal College of General Practitioners, 1972

3 Royal College of General Practitioners. Rating scales for vocational raining in general practice. London: Royal College vocational raining in general practice. London: Royal College

The general practitioner in Europe. A statement by the working party appointed by the Second European Conference in the Teaching of General Practice. Leeuwenhorst, Netherlands, 1974.

5 More W, Maguire J. Handling aggression and violence in health services. London: BMA Publications, 1995.

6 Shepherd J. Violence in health care. Oxford: Oxford University Press, 1994.

\title{
General practice: a secondment from emergency medicine-so what!
}

\author{
Mark F Nicol, Chris A J McLauchlan
}

\author{
Accident and \\ Emergency \\ Department, Royal \\ Devon and Exeter \\ Healthcare Trust, \\ Barrack Road, Exeter \\ EX2 5DW \\ M F Nicol \\ C A J McLauchlan \\ Correspondence to: \\ Dr Nicol. \\ Accepted for publication \\ 16 March 1998
}

\author{
Abstract \\ The Joint Committee for Higher Medical \\ Training has issued a core curriculum for \\ training in accident and emergency medi- \\ cine. This article highlights some of the \\ knowledge, skills, and attitudes one may \\ usefully gain from a period of 6-12 months \\ in general practice and how this can be \\ integrated and adapted to a career in \\ emergency medicine. \\ ( $($ Accid Emerg Med 1998;15:218-219)
}

\section{Keywords: general practice attachment; training}

Having clear aims and objectives for secondments is necessary to gaining the most out of them. A common perception among UK emergency department clinicians who have not spent time in general practice, is that it is of little use to emergency medicine. This situation is reflected in the lack of recognition of a year in general practice towards specialist training by 